\title{
Measuring Small Business Owners' Differences In Moral Thought: Idealism Versus Relativism
}

\author{
Johannes A. Wiid, University of South Africa (UNISA), South Africa \\ Michael C. Cant, University of South Africa (UNISA), South Africa \\ Claudette van Niekerk, University of South Africa (UNISA), South Africa
}

\begin{abstract}
The failure of internationally renowned organisations together with the global financial catastrophe in 2008, which emerged as a result of the collapse in corporate governance, in general, and business ethics, in particular, has led to an amplified focus on business ethics around the world. This has led to governments, private sector, and even individuals to call for stronger regulation and control of business practices in order to stamp out, or at least to reduce, instances of morally and ethically questionable practices.
\end{abstract}

The main purpose of this study was to measure small business owners' differences in moral thought based on idealism and relativism. This is measured by determining the ethical ideological classification of individuals based on Forsyth's ethical taxonomy. The research followed a quantitative analysis and an online survey questionnaire was used to collect the data from Small and Medium Enterprise (SME) owners in South Africa. The results found that the majority of SME owners fall in the situationist and absolutist category of Forsyth's ethical taxonomy.

Keywords: Ethics; Morals; Idealism; Relativism; Small Businesses; South Africa

\section{INTRODUCTION}

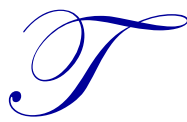

he past number of years has seen the business world rocked by scandals of unethical behaviour, corruption and many other morally deprived actions which are not limited to particular groups, but are prevalent in large, medium, and small organisations where moral decay is at the order of the day. Much of this can be attributed to the failure in corporate governance in general, and business ethics in particular. This has led to an amplified focus on business ethics around the world. Governments, private sector companies, and even individuals have voiced their call for stronger regulation and control of business practices in order to stamp out, or at least to reduce, instances of morally and ethically questionable practices.

Ethics have become the buzz of the business world and are widely spoken about these days due to the fact that the moral assurance of the past is long gone. In earlier times, communities had confidence in the moral harmony that was shared among families, religions, organisations, academics, government, and the legal systems (Stulting, 2000, p. 379). Today, on a global perspective, there is a diverse plethora of cultures and ethnic groups living in a society with many opposing morals, values, and ethics (Stulting, 2000, p. 379). Consequently, operating in the complex business environment of today, which is still experiencing the effects of a major economic downturn, many businesses have found it difficult to survive and be profitable. This drive for survival and profitability places tremendous pressure on the practices employed by organisations and the way they conduct business. The pressure to survive may influence their propensity to act in an unethical manner and as this pressure is amplified, an increased level of unethical behaviour in the business environment may occur.

Business ethics is also part of the South African landscape, both on a practical and an academic level. In South Africa, there seems to be a perpetual stream of media reports broadcasting the unethical behaviour of senior 
business decision-makers, government or political leaders, and leaders in all industries (Van der Walt, 2010). Since 2010, business headlines were inundated with reports of multi-million rand organisations being hijacked through dubious practices, the fabrication of documentation, match fixing in sport, and the selling of shares in Ponzi-type schemes through syndicates (Van der Walt, 2010). This has led to new legislations and codes being introduced in South Africa in an attempt to limit or reduce unethical behaviour and to increase standards in businesses (Van der Walt, 2010). Raga and Taylor (n.d) argued that the South African government and the public cannot support and implement ethical behaviour merely through the exploitation of ethical codes of conduct or the dissemination of an overabundance of legislations. There has been a call for an increase of ethical behaviour and conduct by all leaders in academia, government, and business.

The fact that ethical behaviour is questioned by all relevant groups and has become a major focal point is the rationale behind this article, which attempts to determine the moral stance of Small and Medium Enterprise (SME) owners in South Africa and ultimately determining their perception of ethics and the managerial operations of these SMEs. The reason for this focus lies in the fact that the authors believe that business people's attitudes or opinions of certain ethical and moral issues will impact on their potential to act unethically.

This study, which focuses on the moral thought of SME owners in South Africa, attempted to establish in which ethical classification they fell based on idealism and relativism. The literature will therefore focus on ethics, business ethics, and Forsyth's Ethical Positioning Questionnaire (EPQ) that was employed in this study. In the subsequent section of this paper, the objective and research methodology will be discussed followed by the research findings, and a conclusion.

\section{ETHICS AND BUSINESS ETHICS}

The ethical environment is a relatively new sub-discipline with the intention to rationalise moral motivations and beliefs for the purpose of environmental protection (Raisner, 1997, p. 1331; Yang, 2006, p. 23). Many authors have described ethics as being the branch of philosophy that is concerned with issues of morality determining right from wrong, good from bad, moral from immoral, and fair from unfair (Mujtaba, 2005, p. 1; Quigley, 2008, p. 253; Van der Walt, 2010). Okafor (2011, p. 34) states that ethics is the principle of morality, which is both the science of the good and the nature of the right. Furthermore, Khomba and Vermaak (2012, p. 3511) describe ethics as a set of rules or a code of behaviour that characterises right from wrong and that assists individuals in differentiating between fact and belief, choosing how such issues are defined and what moral values apply to the situation. Ethics are therefore "... moral guidelines that govern good behaviour" (Okafor, 2011, p. 34; Riley, 2012). Essentially, behaving ethically is doing what is morally right.

Philosophers, theorists, and academics generally distinguish ethics from morality, as morality refers to human conduct and values and ethics refer to the study of human character or behaviour in relation to moral values (Fernando, 2010). This means that ethics is the study of moral standards whose overt purpose is to establish whether a given moral standard is more or less correct (Velasque in Fernando, 2010). Furthermore, while individual ethics refer to the set of moral values that form the moral fibre and behaviour of an individual, organisational ethics describe what constitutes right from wrong or good from bad in human conduct in a business context (Fernando, 2010). Business ethics deal with all issues pertaining to the work behaviour, including the ethical principles and moral or ethical problems that arise in the business environment. Businesses must adhere to their ethical behaviour in their day-to-day operations as this forms the moral fibre of the organisation (Crystal, 2013; Velentzas \& Broni, 2010, p. 795). Shakeel, Khan, and Khan (2011, p. 59) define business ethics as “... the recognition and implementation of commonly agreed-upon standards of conduct that ensures the company will not impact its stakeholders negatively." In simpler terms, one can see business ethics as what is regarded as right and wrong or good and bad human behaviour in a business setting.

\section{FORSYTH'S ETHICS POSITIONING QUESTIONNAIRE (EPQ)}

Researchers and academics have developed various measures in order to understand the difference between individuals as they make moral judgements (Yurchisin \& Johnson, 2010, p. 17). The most used measure that was designed to determine the variations in individual's ethical viewpoints are the Ethical Positioning Questionnaire 
(EPQ). The EPQ was developed by Donelson Forsyth in the 1980s for the purpose of categorising individual's personal stance on ethics (Quigley, 2008). The EPQ has been used with diverse populations and has shown to be vastly indicative of how individuals are likely to approach and resolve ethical dilemmas (Ward, 2013).

The EPQ is based on an individual's perception or attitude toward ethics in relation to idealism and relativism, which reveals the descriptive power of ethical decisions in businesses (Forsyth in Park, 2005, p. 85). Idealism and relativism refer to the individual differences that manipulate one's judgements of moral concerns (Park, 2005, p. 85). Idealism can be seen or explained as the degree of dealing with the search for humanitarian aspirations - believing that everyone is concerned with the well-being of other people. Others might be less idealistic about the world and may place less emphasis on the well-being of other people (Plaisance, 2009). These people might consider impending harm as something that must be measured in the context of the overall good. In other words, harm to others may be necessary to produce some good and is therefore ethical (Plaisance, 2009). As opposed to idealism, there is relativism, which refers to the conviction that the only way one can make a decision about what is regarded as ethical and what not, is to rely on one's own experiences, knowledge and internal moral compass (Plaisance, 2009). Relativism is further explained by Van der Walt (2010, p. 10) as the concept of truth, justice and ethics, which are not absolute and must be assessed within its social context.

Collectively, an individual's degree of idealism and their way of thinking relativistic constitute what is called an individual's ethical ideology - a person's belief system (Plaisance, 2009). The 20-item EPQ scales developed by Forsyth measures both the degree of idealism to which the individual subscribes as well as the extent to which the individual rejects universal moral rules in favour of relativism (Ward, 2013). The measure allows researchers to categorise individuals into one of four different quadrants or groups; namely, situationalists, absolutists, subjectivists, and exceptionalists (Yurchisin \& Johnson, 2010, p. 17). The taxonomy that classifies individuals' ethical stances into four ideologies, as show in Figure 1, is based on high and low idealism and relativism scores.

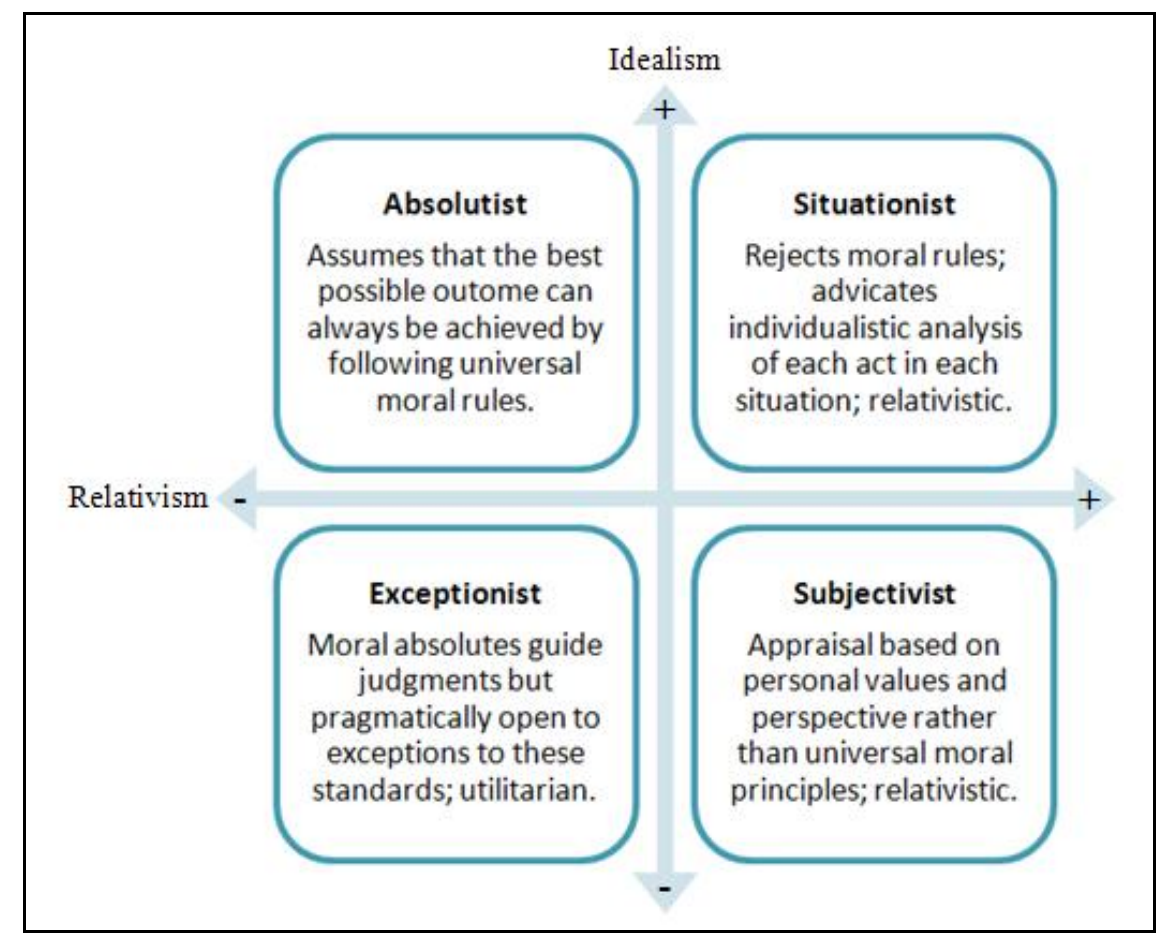

Figure 1: Classification of Ethical Ideologies According to Forsyth's Model (1980) Source: Ward (2013)

As illustrated in Figure 1, there are four classifications of individuals' ethical ideologies. First, a situationist demonstrates a high degree of idealism, as well as relativism, and thus discards moral rules and believes that ethical 
decisions are always practical to the situation (Yurchisin \& Johnson, 2010, p. 17). Second, a subjectivist also portrays a high degree of relativism; however, they exhibit a low degree of idealism. The lack of external moral standards means that what is considered to be right can only be determined by one's own personal values and perspectives (Ward, 2013). Third, the absolutist displays a high degree of idealism and a low degree of relativistic measures. This reflects the notion that moral judgements are based on personal values and perspectives (Yurchisin \& Johnson, 2010, p. 17) and the 'rightness' of an act depends on the consequences of the action (Ward, 2013). The fourth and last classification of ethical ideology is the exceptionist, which scores a low degree on both idealism and relativism (Ward, 2013). The exceptionist deems universal moral rules as vital, however, implementing such rules should be made by taking into account the justifying contexts of the situation as well as the circumstances and consequences (Ward, 2013).

\section{RESEARCH OBJECTIVE}

The main purpose of this study was to measure differences in moral thought based on idealism and relativism among small business owners in South Africa. This is measured by determining the ethical ideological classification of individuals based on Forsyth's ethical taxonomy.

It is evident that there are various factors that influence the ethical and moral behaviour of an individual and that people go through a moral decision-making process to determine whether the situation is right or wrong. Therefore, the study aims to determine in which of the four ethical classifications small business entrepreneurs in South Africa belong to, which will ultimately determine the ethical stance of these owners and businesses. Determining this will ultimately indicate the perception that SME entrepreneurs have toward the ethical aspects of managing their business and employees and whether or not operating ethically is more important to them than making a profit.

The methods that were used in order to obtain the relevant data are discussed in the next section followed by the empirical findings and a discussion of the findings.

\section{RESEARCH METHODOLOGY}

The research followed a quantitative analysis and an online survey questionnaire (Survey Monkey) was used to collect the data from SME owners in South Africa. A total of 95 usable responses were received from owners of SME's in South Africa who either started their own business or are in the process of starting up their own business.

The questionnaire contained ten statements (items) on each of the ethical positioning constructs of Idealism and Relativism and it makes use of a 9-point Likert scale: completely disagree, largely disagree, moderately disagree, slightly disagree, neutral, slightly agree, moderately agree, largely agree and completely agree. The EPQ, which the study was based on, has been tested widely and shown to be reliable, valid and not correlated with social desirability (Ward, 2013). The items included in the questionnaire for the constructs of Idealism and Relativism are shown in Table 1.

Table 1: Items Included in the Questionnaire

\begin{tabular}{|l|}
\hline Idealism \\
\hline People should make certain that their actions never intentionally harm another even to a small degree. \\
\hline Risks to another should never be tolerated, irrespective of how small the risks might be. \\
\hline The existence of potential harm to others is always wrong, irrespective of the benefits to be gained. \\
\hline One should never psychologically or physically harm another person. \\
\hline One should not perform an action which might in any way threaten the dignity and welfare of another individual. \\
\hline If an action could harm an innocent other, then it should not be done. \\
\hline $\begin{array}{l}\text { Deciding whether or not to perform an act by balancing the positive consequences of the act against the negative consequences } \\
\text { of the act is immoral. }\end{array}$ \\
\hline The dignity and welfare of the people should be the most important concern in any society. \\
\hline It is never necessary to sacrifice the welfare of others. \\
\hline Moral behaviours are actions that closely match ideals of the most "perfect" action. \\
\hline
\end{tabular}


Table 1 cont.

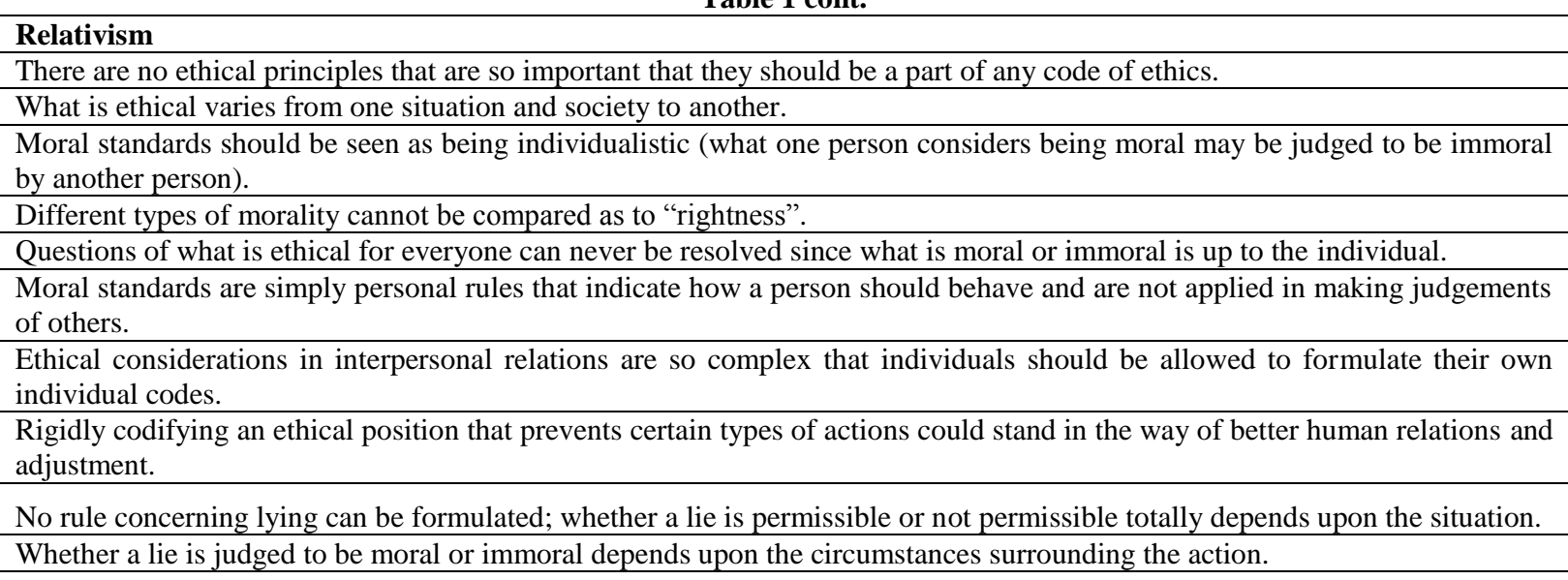

A single score was determined for each respondent per construct by calculating the mean of the individual scores. These scores were allocated coordinates on a Cartesian plane to determine the classification of individuals based on Forsyth's ethical taxonomy. The four quadrants of the plane (following the normal mathematical convention of quadrant categorisation) distinguish situationist, absolutist, exceptionist, and subjectivist moral business behaviours.

\section{RESEARCH FINDINGS}

The demographic profile of the respondent group is presented in Table 2. More than half (55.2\%) of SME owners were between 26 and 35 years of age. The gender split for the respondent group is male dominated (68.4\%). More than three quarters $(76.6 \%)$ of the SME's have less than ten staff members.

Table 2: Demographic Profile

\begin{tabular}{|c|c|c|}
\hline Gender & $\mathbf{N}$ & $\%$ \\
\hline Female & 30 & $31.6 \%$ \\
\hline Male & 65 & $68.4 \%$ \\
\hline \multicolumn{3}{|l|}{ Age } \\
\hline $18-25$ & 8 & $8.3 \%$ \\
\hline $26-35$ & 53 & $55.2 \%$ \\
\hline $36-45$ & 26 & $27.1 \%$ \\
\hline $46-55$ & 8 & $8.3 \%$ \\
\hline$>55$ & 1 & $1.0 \%$ \\
\hline \multicolumn{3}{|c|}{ Number of Staff } \\
\hline$<10$ & 72 & $76.6 \%$ \\
\hline $10-25$ & 6 & $6.4 \%$ \\
\hline $26-50$ & 6 & $6.4 \%$ \\
\hline $51-100$ & 3 & $3.2 \%$ \\
\hline $101-200$ & 2 & $2.1 \%$ \\
\hline$>200$ & 5 & $5.3 \%$ \\
\hline
\end{tabular}

\section{The Taxonomy of Ethical Positioning (According to Forsyth)}

Forsyth classified and placed ethical ideologies into four groups - absolutist, situationist, receptionist, and subjectivist. The classifications of individuals' ethical ideologies are illustrated in Figure 1. To categorise the responses of this study into the taxonomy suggested by Forsyth, overall scores of each respondent were calculated by determining the mean score for the items of the themes that constitute Idealism and Relativism. Overall scores will therefore range between 1 and 9. The distributions yielded from the overall scores are displayed in Figures 2 and 3: 


\begin{tabular}{|c|c|c|}
\hline \multicolumn{3}{|l|}{ IDEALISM } \\
\hline \multirow{4}{*}{$\cdots$} & \multirow{4}{*}{ 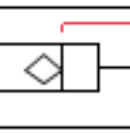 } & \multirow{2}{*}{$\begin{array}{c}\text { Value } \\
9\end{array}$} \\
\hline & & \\
\hline & & 9 \\
\hline & & 9 \\
\hline \multirow{8}{*}{4} & \multirow[b]{7}{*}{8} & 9 \\
\hline & & 8.4 \\
\hline & & 8 \\
\hline & & 7.2 \\
\hline & & 6.388889 \\
\hline & & 4.85 \\
\hline & & 4.5 \\
\hline & Idealism score & 4.5 \\
\hline \multicolumn{2}{|c|}{ Summary Statistics } & \\
\hline Parameter & Value & \\
\hline Mean & 7.756316 & \\
\hline Std Dev & 1.010446 & \\
\hline $\mathrm{N}$ & 95 & \\
\hline
\end{tabular}

Figure 2: Distribution of Mean Scores - Idealism

The scores for Idealism range from 4.5 to 9 with a mean score of 7.75 and a median value of 8 . Variations about these centre positions are given by the standard deviation and the inter-quartile range. These dispersions are 1.01 and 7.2 to 8.4 , respectively.

The Idealism scores tend to be high with $25 \%$ of the values being below 7.2 and $25 \%$ of the values above 8.4.

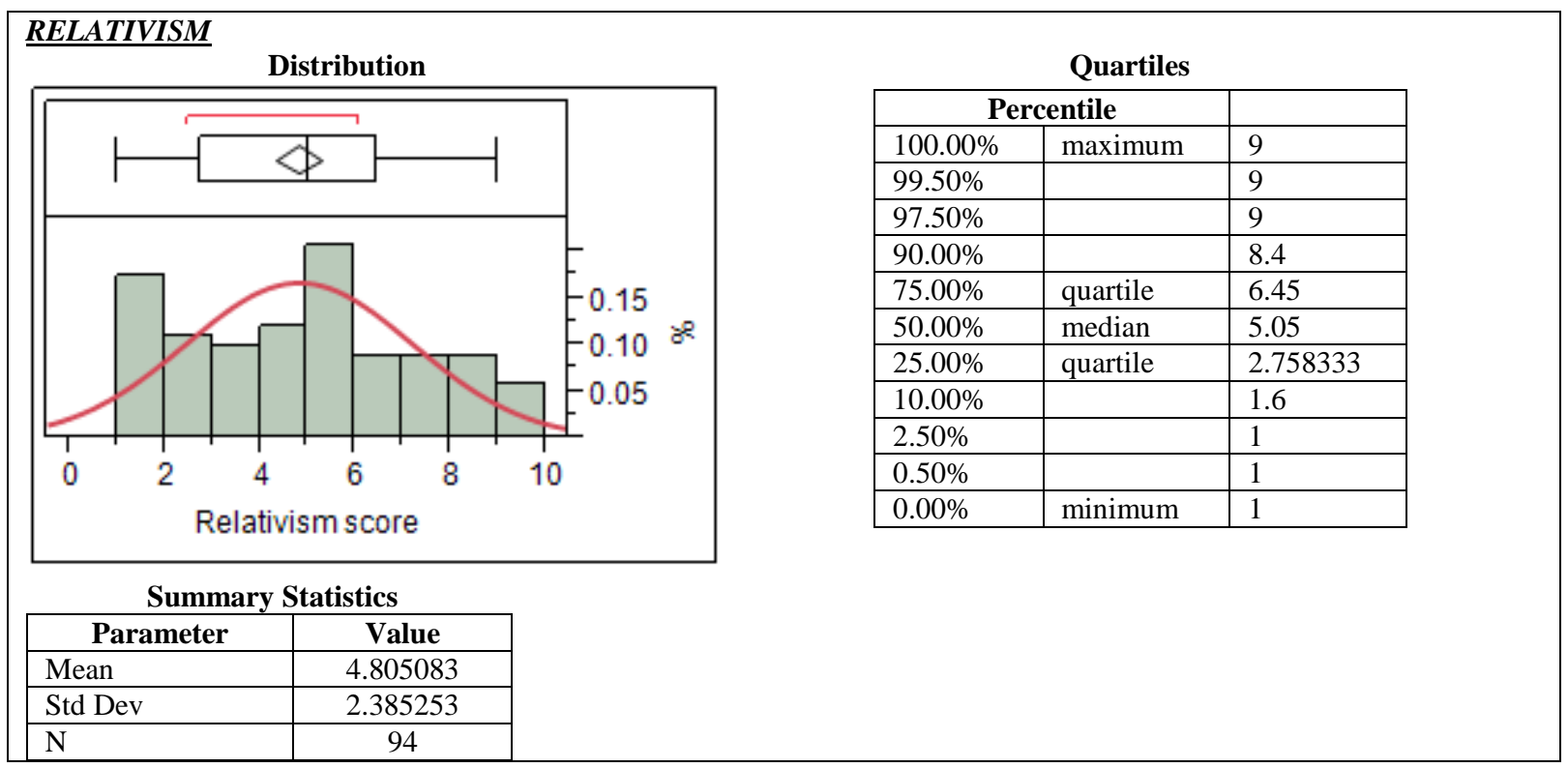

Figure 3: Distribution of Mean Scores - Relativism

The scores for Relativism range from 1 to 9 with a mean score of 4.8 and a median value of 5.05. Variations about these centre positions are given by the standard deviation and the inter-quartile range. These dispersions are 2.38 and 2.76-6.45, respectively. 
The Relativism scores tend to be approximately midway over the range of the measurement scale with $25 \%$ of the values being below 2.76 and $25 \%$ of the values above 6.45 .

The Idealism scores are, in general, higher than the Relativism scores. To bring the scores of Idealism and Relativism in line with the classification of Forsyth, they were presented on a Cartesian plane with Relativism as the $\mathrm{X}$-coordinate and Idealism as the Y-coordinate for each respondent. The origin of this plane was placed where the $\mathrm{X}$-coordinate is equal to 4.5 and $\mathrm{Y}$-coordinate is equal to 4.5 .

The following scatter plot (Figure 4) will thus classify the scores into the four quadrants (absolutist, situationist, subjectivist, and exceptionist) of Ethical Positioning proposed by Forsyth.

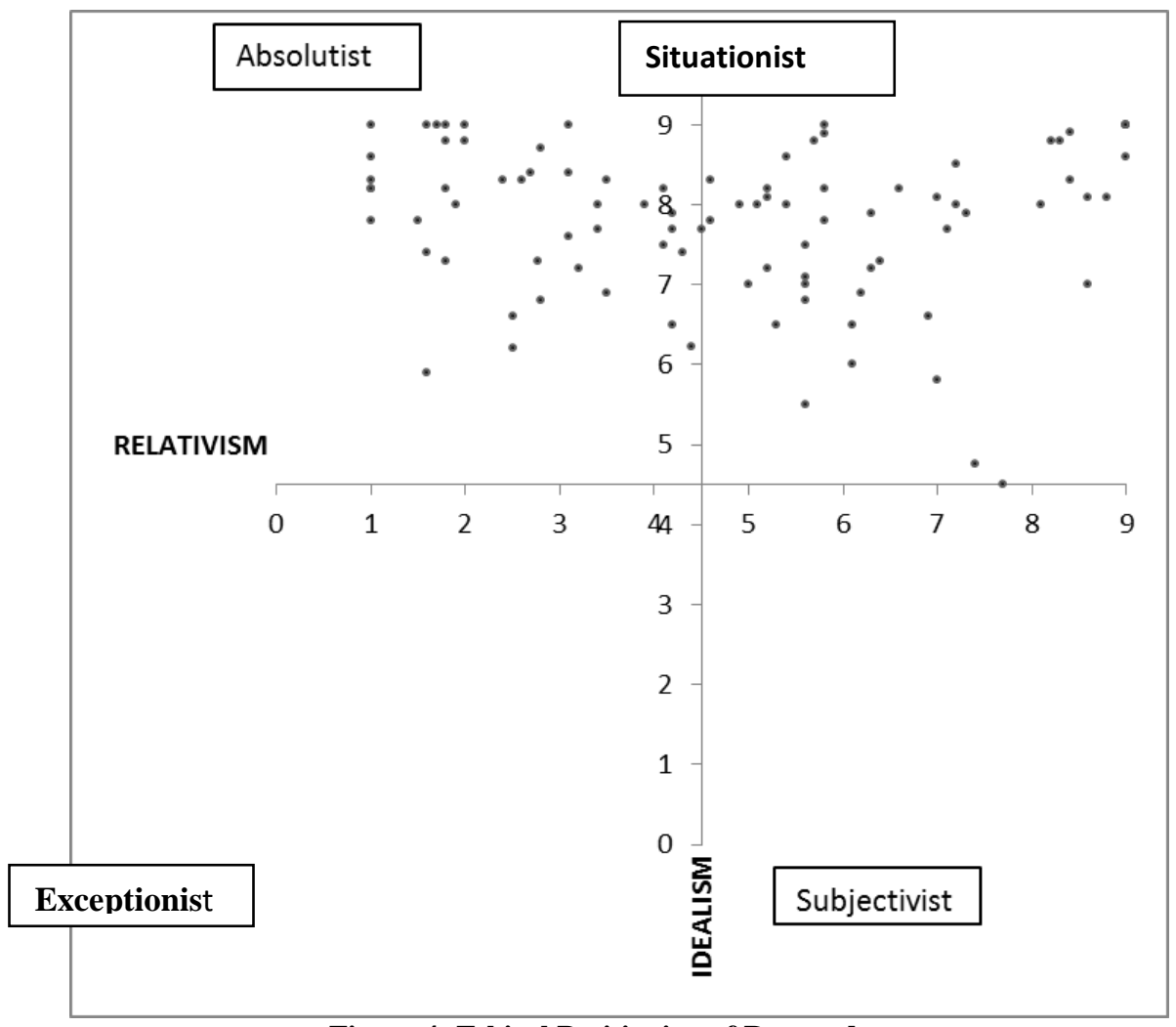

Figure 4: Ethical Positioning of Respondents

As can be seen from Figure 4, the respondents are all located in the absolutist and situationist quadrants and only one respondent was found to be marginally subjectivist.

Table 3 presents the division of the respondents in this survey in the classification above:

Table 3: Division of the Respondents

\begin{tabular}{|l|c|c|}
\hline \multicolumn{1}{|c|}{ Quadrant } & N & \% \\
\hline Absolutist & 43 & $46.2 \%$ \\
\hline Situationist & 49 & $52.7 \%$ \\
\hline Subjectivist & 1 & $1.1 \%$ \\
\hline Exceptionist & 0 & $0.0 \%$ \\
\hline Total & 93 & $100.0 \%$ \\
\hline
\end{tabular}

Of the responses, $46.2 \%$ can be classified as absolutist and $52.7 \%$ as situationist. 
Since the scores of Idealism are all greater than or equal to 4.5 , it is expected that the division between absolutist and situationist will be decided by the Relativism scores. To this end, the division between absolutist and situationist was subjected to partitioning analysis.

To simplify this analysis, the 9-point Likert scale items, upon which ethical positioning of respondents is based, was collapsed to a 5-point scale - strongly disagree, disagree, neutral, agree, and strongly agree.

\section{Partitioning or Decision Tree}

Partitioning data according to a relationship between independent and dependent variables creates a tree of partitions. It finds a set of groupings of the independent variables that best predicts the dependent variable. These partitions (or splits) are done recursively until the desired fit is reached.

The quadrant into which a respondent would fall (absolutist/situationist) was determined by the importance or dominance of members or a group of the 20 items/statements posed of the respondents. The quadrant was thus the dependent variable and the 20 items the independent variables.

Three splits were yielded in the partitioning exercise to predict which statements/items were most likely to determine ethical positioning. These are in order:

- $\quad$ Rigidly codifying an ethical position that prevents certain types of actions could stand in the way of better human relations and adjustment.

- Moral standards are simply personal rules that indicate how a person should behave and are not applied in making judgements of others.

- $\quad$ There are no ethical principles that are so important that they should be a part of any code of ethics.

(Note that the above items originate from the Relativism items of the questionnaire. However, it has already been noted above that the Relativist-axis will determine the division.)

The classification model is significant with a generalised $\mathrm{R}^{2}$ of $88.7 \%$. This variation in the data can be explained by the model. A misclassification rate of only $8.7 \%$ was recorded.

Table 4 is a matrix showing the correct and incorrect classifications:

Table 4: Matrix Classification

\begin{tabular}{|c|c|c|}
\hline Training & Absolutist & Situationist \\
\hline Absolutist & 39 & 4 \\
\hline Situationist & 4 & 45 \\
\hline
\end{tabular}

From this table, it is evident that only four out of 43 (9.3\%) of absolutists are misclassified and only four out of $49(8.2 \%)$ of situationists are incorrectly classified.

\section{Chi-Square Analysis of Association}

The relationship association between prominent determinants of absolutist/situationist, as identified by the partition above, was investigated by the non-parametric Chi-Square test.

Chi-Square test of quadrant versus the prominent determinants yielded significant associations, as indicated in Table 5 and Figure 5. 
Table 5: Chi-Square Test of Quadrant Versus the Prominent Determinants

\begin{tabular}{|c|c|c|c|}
\hline Prominent Determinants & $\begin{array}{l}\text { Pearson Chi- } \\
\text { Square value }\end{array}$ & DF & p-value \\
\hline $\begin{array}{l}\text { Rigidly codifying an ethical position that prevents certain types of actions could stand } \\
\text { in the way of better human relations and adjustment yielded a significant association or } \\
\text { relationship. }\end{array}$ & 57.862 & 4 & $<0.0001$ \\
\hline $\begin{array}{l}\text { Moral standards are simply personal rules that indicate how a person should behave and } \\
\text { are not applied in making judgements of others. }\end{array}$ & 54.955 & 4 & $<0.0001$ \\
\hline $\begin{array}{l}\text { There are no ethical principles that are so important that they should be a part of any } \\
\text { code of ethics. }\end{array}$ & 25.369 & 4 & $<0.0001$ \\
\hline
\end{tabular}
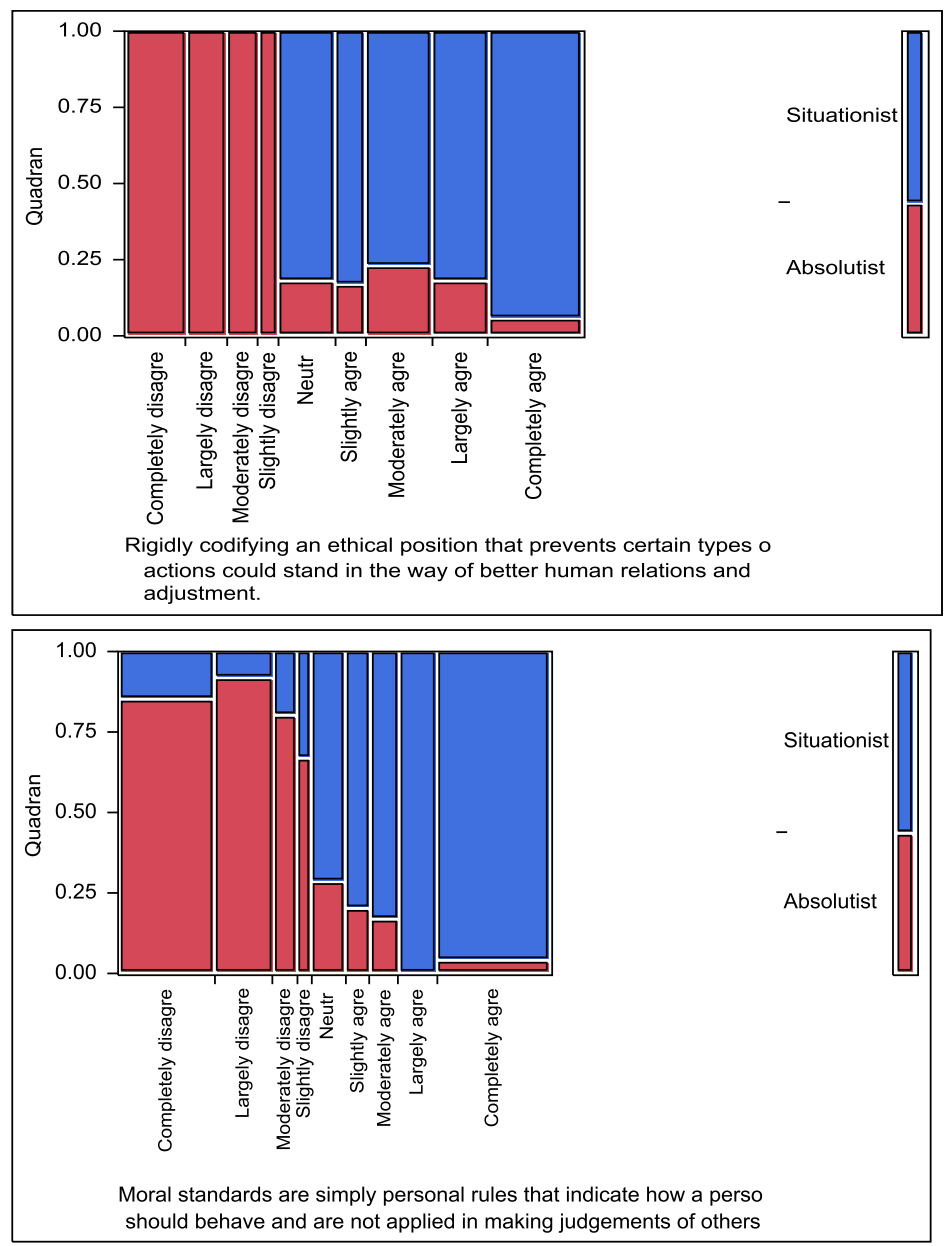

Figure 5: Box Plot 


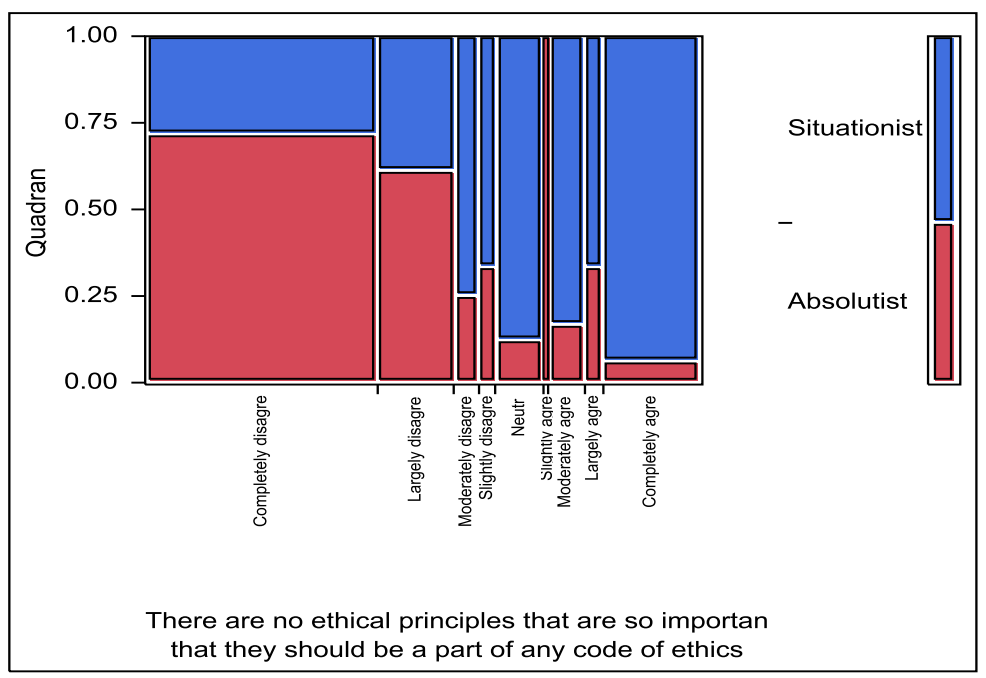

Figure 5 cont.

Absolutists strongly disagree or disagree with the statements while situationists strongly agree or agree.

\section{CONCLUSION}

Ethics refer to a series of rules and principles used to decide what behaviours are right, good, and proper. It defines how things should work according to rules of conduct, prescribed to an individual by an external source such as a profession, business, and social system. Ethical dilemmas include acts of dishonesty, fraud, cover-up, discrimination, promise keeping, bullying, bribery, pornography, theft, and harassment, which can negatively impact small businesses if a member of the staff makes him- or herself accountable to acts of ethical misconduct due to peer and societal disapproval.

Ethical dilemmas can be approached from either a realism or idealism point of view. Realism is a concept prophesising that an individual's point of view has no absolute truth or validity. Instead, it has only relative subjective value according to differences in perception and consideration. In terms of realism, moral principles and ethics will be regarded as applicable in a limited context. Idealism promotes the priority of ideals, principles, values, and goals over concrete realities. It considers individual rights, responsibilities and duties as universal, regardless of the outcome.

An individual's degree of idealism and their way of thinking relativistic constitute an individual's ethical ideology or belief system (Plaisance, 2009). In order to determine this degree Forsyth developed the EPQ scales which measures both the degree of idealism to which the individual subscribes as well as the extent to which the individual rejects universal moral rules in favour of relativism (Ward, 2013). The Forsyth taxonomy allows the categorisation of individuals into one of four different quadrants or groups, namely situationalists, absolutists, subjectivists and exceptionalists (Yurchisin \& Johnson, 2010, p. 17).

The study revealed that South African SME owners lean more towards idealism than relativism. This implies that they value individual rights, responsibilities or duties. It indicates that SME owners fall mainly in the situationist and absolutist quadrants of the Forsyth taxonomy. Just over half $(52.7 \%)$ are placed in the situationist quadrant, which demonstrates a high degree of idealism as well as relativism, and thus discards moral rules and believes that ethical decisions are always practical to the situation. Almost half (46.2\%) fall in the absolutist quadrant, displaying a high degree of idealism and a low degree of relativistic measures. This reflects the notion that moral judgements are based on personal values and perspectives. In practice the absolutist might consider stealing to be always immoral even if it is to promote good; i.e., stealing food to feed a starving family. The situationist will evaluate the situation and reasons for stealing and might consider the act of stealing in this example as acceptable. 
Parties involved in these unethical acts include staff, business associates, and clients. Dealing with staff and clients in a multi-cultural society requires a good understanding of moral principles or truth as it can be relative to language, culture, or biological makeup. A good understanding of consumer protection act and labour is vital as these acts directs and protects consumer rights, as well as employment. It is recommended that SME owners and staff members receive training in cultural diversity and customer relationship management. As well as the consumer protection act and labour law. Enterprises that are doing business with SME owners need to familiarise themselves of the cultural makeup of the enterprises as committing cultural blunders may impact negatively on business deals and profitability.

\section{AUTHOR INFORMATION}

Professor Johannes A. Wiid is a Professor in the Department of Marketing and Retail Management at the University of South Africa (UNISA). He has published numerous articles in refereed journals and is the editor and author of various marketing-related textbooks which are widely prescribed at universities in South Africa. He holds a DCom in Marketing from the University of Johannesburg. E-mail: jwiid@ unisa.ac.za

Professor Michael C. Cant is the head of the Department of Marketing and Retail Management at the University of South Africa (UNISA). He has published over 50 accredited articles in refereed journals and is the editor and author of numerous marketing textbooks which are widely prescribed at universities in South Africa. He has presented papers at more than 45 international conferences all over the world and is a well-respected marketing and retail scholar. He holds a DCom in Marketing from the University of South Africa. E-mail: cantmc@unisa.ac.za (Corresponding author)

Ms Claudette van Niekerk is a lecturer in the Department of Marketing and Retail Management at the University of South Africa. She graduated from the University of Pretoria with a BCom (Hons) in Tourism and is currently undertaking her Master's degree in Business Management at UNISA. Her areas of interest include business ethics and social media. E-mail: vniekc@unisa.ac.za

\section{REFERENCES}

1. Crystal, G. (2013). Business ethics. Retrieved 2013-02-25 from http://www.wisegeek.org/what-is-businessethics.htm

2. Fernando, A. C. (2010). Business ethics and corporate governance ( $2^{\text {nd }}$ ed.). India: Dorling Kindersley, Person Education in South Asia. Retrieved 2013-04-30 from http://books.google.co.za/books?id= UNKQtwaszhYC\&lpg=SA2-PA1\&dq=define\%20ethics\&pg=PR2\#v=onepage \&q=In\%20ordinary $\% 20$ parlance, \%20however, \%20people\%20use \%20these\%20xpressions \%20interchangeably \&f=false

3. Khomba, J. K., \& Vermaak, F. N. S. (2012). Business ethics and corporate governance: An African sociocultural framework. African Journal of Business Management, 6(9), 3510-3518. Retrieved 2013-04-30 from http://repository.up.ac.za/bitstream/handle/2263/21202/Khomba_Business(2012).pdf?sequence=1

4. Mujtaba, B. (2005). Understanding ethics and morality in business. Retrieved 2013-02-19 from http://www.sbnonline.com/2005/04/understanding-ethics-and-morality-in-business-there-are-distinctdifferences-between-ethics-and-morality/

5. Okafor, G. O. (2011). The ethical behaviour of Nigerian business students (A study of undergraduate students' in business schools). Arabian Journal of Business and Management Review, 1(3), 33-44. Retrieved 2013-05-29 from http://www.arabianjbmr.com/pdfs/OM_VOL_1_(3)/4.pdf

6. Park, H. (2005). The role of idealism and relativism as dispositional characteristics in the socially responsible decision-making process. Journal of Business Ethics, 56, 81-98. Retrieved 2013-05-29 from http://link.springer.com/content/pdf/10.1007\%2Fs10551-004-3239-1.pdf

7. Plaisance, P. L. (2009). Media ethics: Key principles for responsible practice. USA: SAGE Publications. Retrieved 2013-04-30 from http://books.google.co.za/books?id=LUJ6s31o_NMC\&lpg=PA14\&dq= Forsyth\%E2\%80\%99s\%20Ethical\%20Positioning\%20Questionnaire\%20(EPQ)\&pg=PR4\#v=onepage\&q= Forsyth\%E2\%80\%99s\%20Ethical\%20Positioning\%20Questionnaire\%20(EPQ)\&f=false 
8. Quigley, M. (2008). Encyclopaedia of information ethics and security. USA: IGI Global. Retrieved 201304-30 from: http://books.google.co.za/books?id=H2VuBddvMLAC\&pg=PT271\&dq=Forsyth\%E2\%80\% 99s+Ethical+Positioning+Questionnaire+(EPQ)\&hl=en\&sa=X\&ei=9K5_UbuDHazT7AbH7oGYDA\&ved $=0 \mathrm{CEQQ6AEwBA}$

9. Raga, K., \& Taylor, D. (No dated). Impact of accountability and ethics on public service delivery: A South African perspective. Retrieved 2013-04-30 from http://www.thepublicmanager.org/articles/docs/kishore.pdf

10. Raisner, J. A. (1997). Using the "ethical environment" paradigm to teach business ethics: The case of the Maquiladoras. Journal of Business Ethics, 16(14), 119-127.

11. Riley, J. (2012). Introduction to business ethics. Retrieved 2013-02-18 from http://www.tutor2u.net/ business/strategy/business-ethics-introduction.html

12. Rossouw, G. J. (1997). Business ethics in South Africa. Journal of Business Ethics, 16(14), 1539-1547. Retrieved 2013-04-30 from http://www.jstor.org/stable/25073021?seq=1

13. Shakeel, M., Khan, M. M., \& Khan, M. A. (2011). Impact of culture on business ethics. Far East Journal of Psychology and Business, 3(2), 59-70.

14. Stulting, A. A. (2000). Ethics in South Africa: new challenges. Med Law, 19(3), 397-401. Retrieved 201304-30 from http://www.ncbi.nlm.nih.gov/pubmed/11143875

15. Van der Walt, A. J. (2010). Changes in attitudes towards business ethics held by past South African business management students. Retrieved 2013-04-30 from http://upetd.up.ac.za/thesis/available/etd07232011-124552/unrestricted/dissertation.pdf

16. Velentzas, J., \& Broni, G. (2010). Ethical dimensions in the conduct of business: Business ethics, corporate social responsibility and the law. The "ethics in business" as a sense of business ethics. International Conference on Applied Economic, 1, 795-819. Retrieved 2013-02-25 from http://kastoria.teikoz.gr/ icoae2/wordpress/wp-content/uploads/articles/2011/10/092.pdf

17. Ward, S. J. (2013). Global media ethics: problems and perspectives. UK: Blackwell Publishing Ltd. Retrieved 2013-04-30 from http://books.google.co.za/books?id=PgxvPXMk9c8C\&pg=PT4\&dq=Forsyth\% E2\%80\%99s+Ethical+Positioning+Questionnaire+(EPQ)\&hl=en\&sa=X\&ei=9K5_UbuDHazT7AbH7oGY DA\&ved=0CDUQ6AEwAQ

18. Yang, T. (2006). Towards an egalitarian global environmental ethics. Retrieved 2013-04-30 from http://publishing.unesco.org/chapters/978-92-3-104039-9.pdf

19. Yurchisin, J., \& Johnson, K. K. P. (2010). Fashion and the consumer. UK: Berg, Oxford International Publishers. Retrieved 2013-04-30 from http://books.google.co.za/books?id=BGAEhPfTXicC\&lpg= PA17\&dq=Forsyth\%E2\%80\%99s\%20Ethical\%20Positioning\%20Questionnaire\%20(EPQ)\&pg=PR4\#v=on epage\&q=Forsyth\%E2\%80\%99s\%20Ethical\%20Positioning\%20Questionnaire\%20(EPQ)\&f=false

20. Zikmund, W. G., \& Babin, B. J. (2007). Essentials of marketing research (3rd ed.). USA: Thomson. 